\title{
International Affective Picture System (IAPS) in Chile: A cross- cultural adaptation and validation study
}

\section{El sistema internacional de imágenes afectivas (International Affective Picture System- IAPS) en Chile: Estudio de adaptación y validación transcultural}

\author{
Jaime R. Silva* \\ Universidad de La Frontera, Chile
}

(Rec: 14 de Junio de 2011 / Acep: 10 de Octubre de 2011)

\begin{abstract}
The International Affective Picture System (IAPS) (Lang, Ohman, \& Vaitl, 1988) is a standardized set of photographs to induce emotions in the context of experimental investigations. The aim of this study was determine the psychometric behavior of the IAPS for the preparation of standards in the Chilean population and the subsequent validation of the instrument for its use in Chile. 208 university students participated (40\% men) and had an affective experience induced using the presentation of visual stimuli extracted from sets 7 and 14 of the IAPS. In order to evaluate valence, arousal and dominance, the self-assessment manikin (SAM) was used, made up of pictographic scales for each dimension and a scale of continuous variation of emotional reactions. The IAPS showed psychometric behavior comparable to the original, with the same boomerang-shaped distribution of scores being found in the valence/arousal relationship. The IAPS is a reliable tool for inducing emotions in studies related to affectivity.
\end{abstract}

Keywords: International Affective Picture System, cross-cultural validation

\section{Resumen}

El Sistema Internacional de Imágenes Afectivas (International Affective Picture System-IAPS) (Lang, Ohman, \& Vaitl, 1988) es un conjunto estandarizado de fotografías para la inducción de emociones en el contexto de investigaciones experimentales. El objetivo de este estudio fue conocer el comportamiento psicométrico del IAPS para la confección de normas en la población chilena y la validación consiguiente del instrumento para su uso en Chile. Participaron 208 estudiantes universitarios (40\% hombres) a quienes se les indujo una experiencia afectiva mediante la presentación de estímulos visuales extraídos del set 1 y 14 del IAPS. Para evaluar valencia, arousal y dominancia, se utilizo el maniquí de auto-evaluación o SAM (Self - Assessment Manikin), compuesto por escalas pictográficas para cada dimensión y una escala de variación continua de reacciones emocionales. El IAPS muestran un comportamiento psicométrico comparable al original, encontrándose la dispersión de puntajes de boomerang en la relación Valencia/Arousal. El IAPS es una herramienta confiable para la inducción de emociones en estudios ligados a la afectividad.

Palabras claves: Sistema Internacional de Imágenes Afectivas, validación transcultural

* Correspondence: Departamento de Salud Mental y Psiquiatría. Facultad de Medicina Universidad de La Frontera. Av. Alemania, Temuco, Región de la Araucanía-Chile Phone: (56) (45) 592177 e-mail: jaimesilva@ufro.cl

Acknowledgements : This research was financed by the Dirección de Investigación of the Universidad de La Frontera (DIUFRO), the Dirección de Cooperación Internacional of the Universidad de La Frontera and FONDECYT 11090162. 


\section{Introduction}

The International Affective Picture System (IAPS) was created at the NIHM Center for the Study of Emotion and Attention at the University of Florida with the aim of providing a set of pictorial stimuli for use in experimental investigations to elicit emotion (Lang, Ohman, \& Vaitl, 1988). This system is made up of a set of visual stimuli that comprises various aspects of real life with an ample range of semantic categories. Generally these pictures are able to generate emotional activation similar to what occurs under real conditions, inducing mental representations, psychophysiological changes and facial action (Cuthbert, Bradley \& Lang, 1996). Although the use of the IAPS has expanded profusely internationally (for a review see Bradley \& Lang, 2007), in Chile it is hardly used at all (e.g. Silva \& Pizzagalli, 2006).

The theoretical model of the IAPS emphasizes three large dimensions that organize the emotional world on the broadest level: valence, arousal and dominance. Affective valence refers to the body's disposition in situations or events in terms of appetizing or aversive motivational traits (the range of which extends from the very pleasant to the very unpleasant). Arousal is the energy or force in the dominant emotional system (from very calm to very excited). Finally, dominance represents the degree of perceived control over the affective stimulus (from "in control" to "out of control"). These dimensions are related to the active organization of the body prior to different stimulating events that are evolutionarily essential for survival. Given the body's necessity to adapt quickly to environmental conditions, perceptual, cognitive and physiological systems generate responses organized in those dominions.

In order to evaluate the dimensions of valence, arousal and dominance from affective images, the self-assessment manikin (SAM) is used, which comprises pictographic scales that provide information for each dimension. In this system, the subjects use an image that represents the values in each one of the three dimensions with a scale of continuous variation to indicate emotional reactions. This way, the subjects exposed to the IAPS photographs can select any one of the five images included on each scale or from between either of the two images that results in a scale of nine points for each dimension (Lang, Bradley \& Cuthbert, 2001). The responses are classified so that the number 9 represents the highest classification of each dimension, i.e., a high degree of pleasure, activation and dominance, whereas the number 1 is the lowest classification of each dimension, i.e., a low level of pleasure, arousal and dominion.

One of the most interesting observations derived from international studies on the IAPS is the affective space that emerges from the valence-arousal relationship. Indeed, when representing the results on a scatter plot, a distribution in the shape of a boomerang has been obtained consistently, which shows differential gradients of the valence/arousal relationship for both the pleasant or unpleasant images. Thus, from a neutral affective base, two branches fork out towards two extremes of valence, which describe high levels of activation or arousal.

The aim of this study was to determine the psychometric behavior of sets 7 and 14, in the dimensions of valence, arousal and dominance, from the IAPS in a sample of Chilean university students.

\section{Method}

\section{Participants}

The total sample is composed of 208 undergraduate students from the Universidad de La Frontera. Of the total participants, 124 were women (60\%) and 84 were men $(40 \%)$. The average age was $19(\mathrm{SD}=1.2)$.

During the application of the instrument, 3 people refused to participate in the study and 1 was ruled out for not following the instructions correctly.

\section{Instruments}

The IAPS (Lang, Ohman, \& Vaitl, 1988) was used, which consists of photographs with a broad range of semantic categories, divided into 16 sets of around 60 photos each. In this study two sets from the IAPS were used (7 and 14) with a total of 119 images.

The photos shown to the participants according to presentation order were the following: $2191,2055,2346$, 2357, 2635, 2981, 4626, 7041, 8186, 8620, 9471, 9921, 2691, 3102, 4535, 5001, 5532, 7002, 7502, 8161, 1731, 2442, 7504, 1201, 4534, 5201, 7284, 9373, 2071, 2579, $4503,7179,8485,1811,4641,7233,8040,9470,1726$, $2278,2595,4677,7475,8192,9342,1931,4608,5629$, 7234, 8033, 9008, 9432, 1205, 2095, 2375, 2795, 4538, 7037, 7250, 8475, 9472, 2661, 4001, 4603, 4664, 6830, 7285, 9006, 9411, 9911, 1661, 1935, 2222, 2399, 2688, $3101,4624,5661,7359,8251,9409,9495,1302,2092$, 4002, 4609, 5531, 6313, 7009, 7235, 8034, 9182, 9571, $1111,9635,2025,2224,2435,2745,4141,4625,7036$, 7236, 8191, 9301, 1114, 2091, 3053, 4004, 4607, 4659, 5621, 7224, 7286, 8162, 9252, 9452, 9621, 9622.

\section{Procedure}

The IAPS was applied in groups (up to 25 subjects per session) under similar lighting conditions, with independent and similar armchairs, projecting each photo onto a curtain. Each participant was given a consent letter, explaining the features of the experiment. Those who wished to participate were then given the SAM answer sheet, the instructions were explained and the photographs were then shown sequentially. The instructions were presented following 
Table 1: Average of valence, arousal and dominance for sets 7 and 14 in Chile (this study), Brazil and the United States.

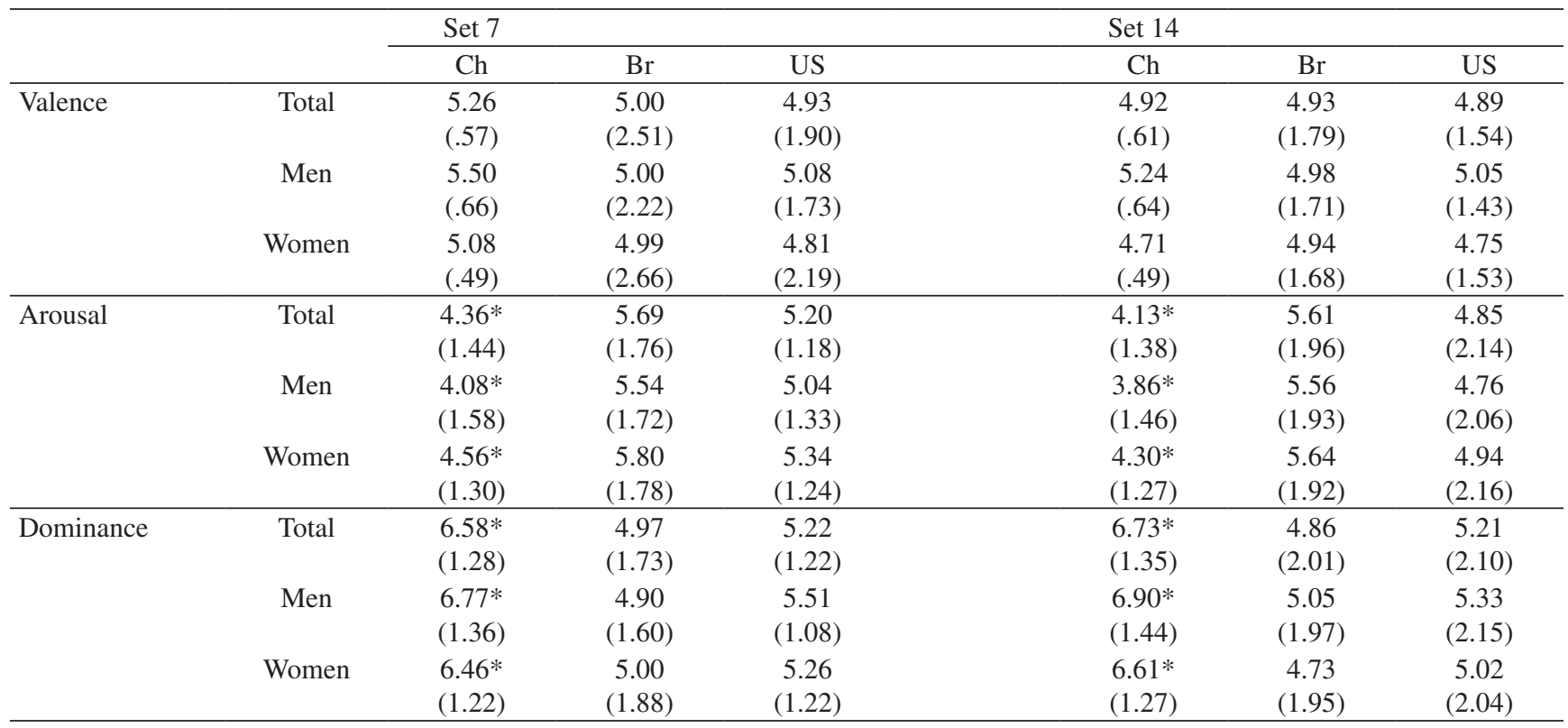

Note: $\mathrm{Ch}=$ Chile; $\mathrm{Br}=$ Brazil; US=United States. ${ }^{*} p<.05$

the standardized guidelines of Lang, Bradley and Cuthbert (2001). The experiment began with three test photographs, which displayed the standardized presentation format and instructions for the evaluation. For each photograph to be evaluated, a slide appeared for 5 seconds that prepared the subjects for the presentation of the corresponding picture, indicated as follows: "Get ready to evaluate the next photo", then the photograph was displayed for 6 seconds. Then the following instruction appeared for 15 seconds: "Write your answer on sheet $\mathrm{x}$, line $\mathrm{x}$ ". Then the preparation slide was shown to them again and so on until the last photo displayed. The 208 participants observed 119 images.

\section{Results}

In Appendix 1 there is a listing of the 119 images and their valuation of valence, arousal and dominance, according to gender. Table 1 presents the averages of the responses that the participants gave for the 119 images, as well as the gender differences that emerged in this valuation. As a reference the averages obtained by international studies conducted in the US (Lang, Bradley \& Cuthbert, 2001) and Brazil (Larsen, Pompéia, \& Amodeo, 2005; Lasaitis, Larsen, \& Amodeo, 2008) are provided. As can be seen, in set 7 the women reported a slightly higher level of arousal $\left(t_{(208)}=-2.513, p<.05\right)$ an a lower level of valence $\left(t_{(208)}=5.881\right.$, $p<.001)$ than the men. In the same way, in set 14, arousal was greater in the women $\left(t_{(208)}=-2.489, p<.05\right)$ and valence was greater in the men $\left(t_{(208)}=7.148, p<.001\right)$. As for dominance, no significant differences emerged from gender (all $p>.05$ ).
With respect to the cultural differences suggested by Table 1 (less arousal and greater dominance in Chile), it might be argued that these originate from idiosyncratic traits of the target country, but also, and more likely, as an effect of recent adversities in Chile (Vogel \& Vera-Villarroel, 2010). These adversities may lead to changes in perception and affective experience (Echeburua, 2010; Cova and Rincón, 2010) that in the case of the IAPS could lead to lower responsiveness to this class of stimuli.

When considering affective space, the dispersal of the images according to their valence/arousal valuation produced a "boomerang" configuration for the sample according to gender (see Figure 1). This relation, although significant when calculated using linear estimation $(r=-.477$; $p<.05)$, is more appropriately described as a curvilinear relation (Ito, Cacioppo, \& Lang, 1998; Lang, Bradley \& Cuthbert, 2001). Indeed, as can be observed in Figure 2, when estimating arousal from valence, a significant quadratic effect was obtained $\left(F_{(2,116)}=73.044 ; p<.001\right)$.

The analysis of the activation gradient for each dimension of pleasure and displeasure was performed as follows. First, the analysis was divided by considering those images that describe the appetitive affective space separately from those of the aversive space. Then, for each affective space, the simple regression was calculated between the valence and arousal scores. This way, two slopes were obtained, one for each dimension of pleasure/displeasure. In Table 2 the slope of the valence/arousal relationship was observed for the total sample and according to gender. As Lang et al.'s model of motivation-emotion (Lang et al. 1988) 


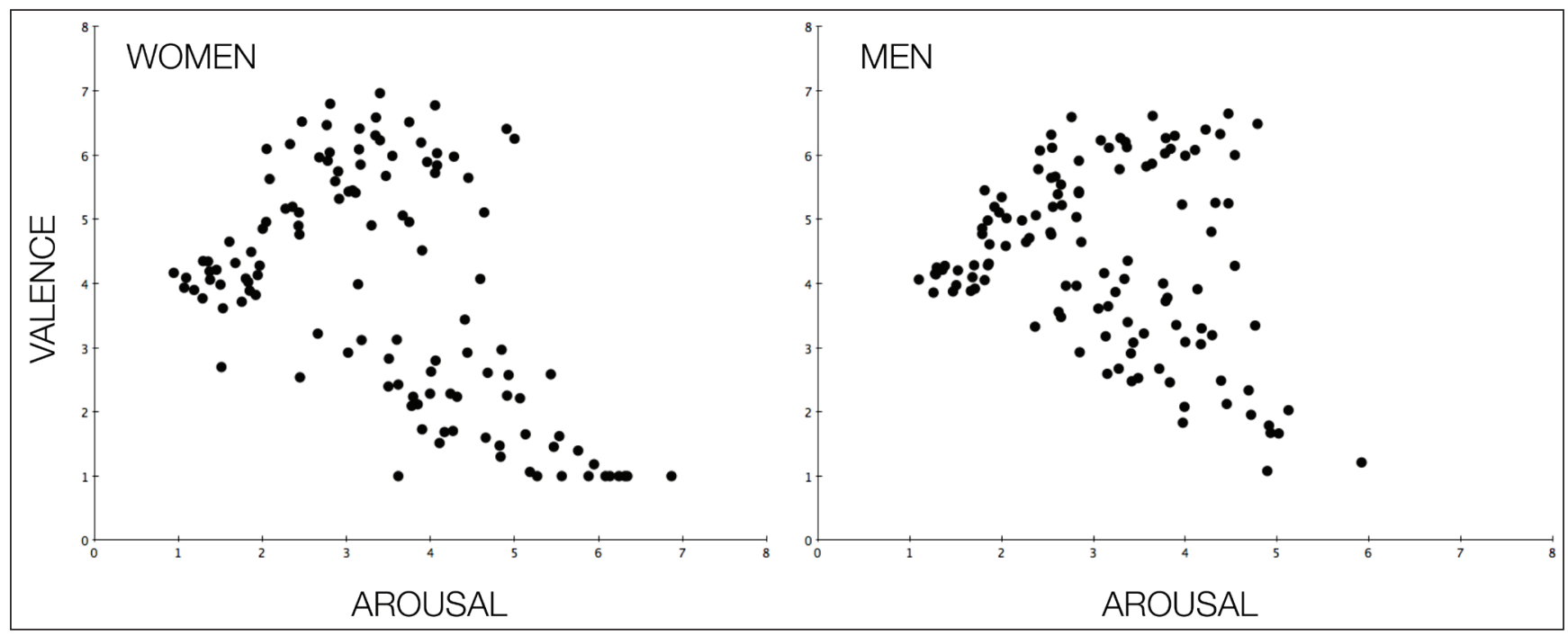

Figure 1: Scatter plots of relation between arousal and valence according to gender.

Note: The data are based on the score obtained for each photograph $(\mathrm{n}=119)$. The distribution of scores in both cases describes a "boomerang" pattern.

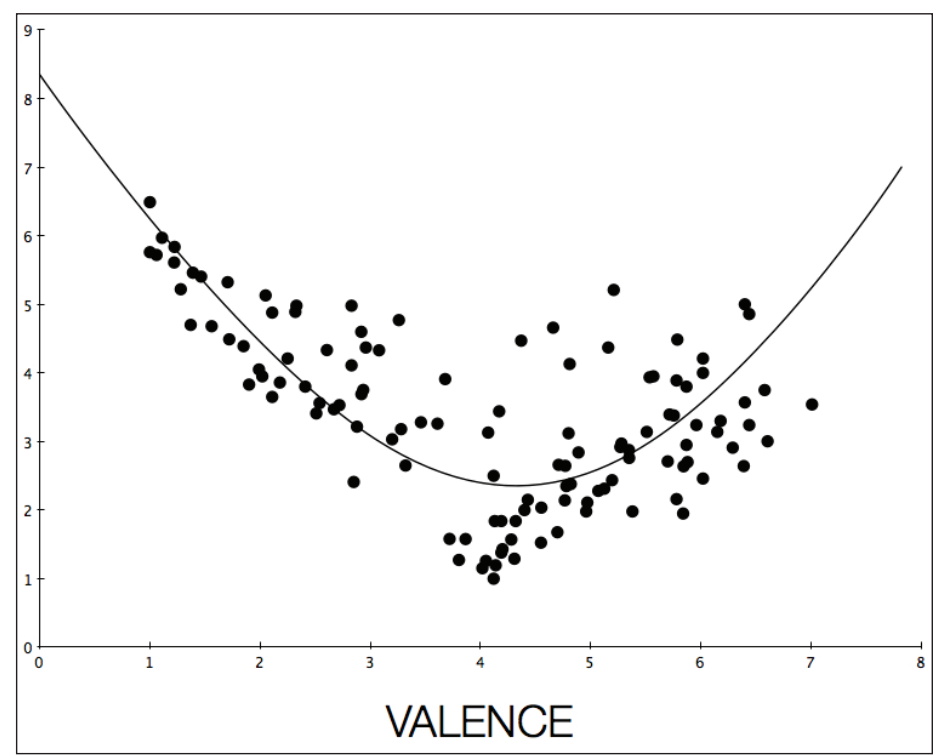

Figure 2: Quadratic estimation of arousal from valence

Note: The data are based on the score obtained for each photograph $(\mathrm{n}=119)$. Displays the line of regression that shows the quadratic effect $\left(F_{(2,116)}=73.044\right.$; $p<.001)$

suggests, the activation gradient in the case of displeasing emotions is more accentuated $(\mathrm{p}<.001)$. Additionally, marginally significant differences in the activation gradient in the case of pleasing emotions are observed, there being a greater gradient in men $(z=1.756 ; p<.079)$. This can be explained by the effect of erotic images, which usually induce more activation in men than in women (Bradley et al. 2001).

\section{Discussion}

As a dual model of emotions (Dalgleish, Dunn, \& Mobbs, 2009) predicts, sets 7 and 14 showed consistent psychometric behavior with the existence of segregated motivational systems, with a quadratic association and the boomerang distribution being found in the valence/ arousal relationship. Moreover, the subjects' responses to the images assessed as negative and positive followed 
Table 2: Activation gradient according to valence (positive/negative) for men and women.

\begin{tabular}{|c|c|c|c|c|c|c|c|c|c|}
\hline & \multicolumn{3}{|c|}{ Total } & \multicolumn{3}{|c|}{ Women } & \multicolumn{3}{|c|}{ Men } \\
\hline & $\beta$ & $t$ & $p$ & $\beta$ & $t$ & $p$ & $\beta$ & $t$ & $p$ \\
\hline Positive & .216 & 1.345 & .187 & .148 & .923 & .362 & .502 & 3.75 & $.001 * *$ \\
\hline Negative & -.80 & -12.81 & $.001 * *$ & -.85 & -12.81 & $.000 * *$ & -.730 & -9.11 & $.001 * *$ \\
\hline
\end{tabular}

Note: $\beta=$ Slope $* * p<.01$

the same principles as reported previously. Specifically, a greater activation gradient was observed for the negative stimuli than for the positive stimuli, which implies that the defensive motivational system responds by generating greater activation or arousal (negative bias). The gender differences regarding the intensity of arousal and valence also confirmed the gender differences associated with the emotional response (Bradley et al. 2001).

Future studies could include other sets of stimuli, but more significant and relevant than that, they would have to analyze in depth the cultural differences that have been suggested from the data described here.

As a whole the data contributed by this research permit the use of sets 7 and 14 of the IAPS in a Chilean population.

\section{References}

Bradley, M. M, Codispoti, M, Cuthbert, B. N, and Lang, P. J. (2001) Emotion and Motivation I: Defensive and Appetitive Reactions in Picture Processing. Emotion, 1, 276-298.

Bradley, M. M., Codispoti, M., Sabatinelli, D., \& Lang, P. J. (2001). Emotion and motivation. II: Sex differences in picture processing. Emotion, 1, 300-319.

Bradley, M. M. \& Lang, P. J. (2007). The International Affective Picture System (IAPS) in the study of emotion and attention. In J. A. Coan and J. J. B. Allen (Eds.), Handbook of Emotion Elicitation and Assessment (pp. 29-46). New York: Cambridge University Press.
Cova, F. \& Rincon, P. (2010). El Terremoto y Tsunami del 27-F y sus Efectos en la Salud Mental. Terapia Psicológica, 28, 179-185.

Cuthbert, B.N., Bradley, M.M. y Lang, P.J. (1996). Probing picture perception: Activation and Emotion. Psychophysiology, 33, 103-111.

Dalgleish, T., Dunn, B., \& Mobbs, D. (2009). Affective Neuroscience: Past, Present, and Future. Emotion Review, 1, 355-368.

Echeburua, E. (2010). El Desafío de la Prevención en Estrés Postraumático: ¿Cómo Sobrevivir a un Desastre?. Terapia Psicológica, 28, 147-154.

Ito, T.A., Cacioppo, J.T., \& Lang, P.J. (1998). Eliciting affect using the International Affective Picture System: Trajectories through evaluative space. Personality and Social Psychology Bulletin, 24, 855-879.

Lang, P.J., Bradley, M.M. \& Cuthbert, B.N. (2001). International Affective Picture System (IAPS): Instruction Manual And Affective Ratings. Technical report A-5, The Center for Emotion and Motivation. Bradley, M.M. Research in Psychophysiology, University of Florida.

Lang, P., Ohman, A., \& Vaitl, D. (1988). The international affective picture system Gainesville, FL: University of Florida, Centre for Research in Psychophysiology.

Larsen, R., Pompéia, S., \& Amodeo, O. (2005). Comparison of Brazilian and American norms for the International Affective Picture System (IAPS). Revista Brasileira de Psiquiatria, 27, 208-215.

Lasaitis, C., Larsen, R. \& Amodeo, O. (2008) Brazilian norms for the International Affective Picture System (IAPS) - comparison of the affective ratings for new stimuli between Brazilian and North-American subjects. Jornal Brasileiro de Psiquiatria, 57, 270-275.

Silva, J. \& Pizzagalli, D. (2006). Cortical response to food stimulus in restrained eaters under ego-threat anxiety: an ERP source localization study. Psychophysiology, 43, S92.

Vogel, E. \& Vera-Villarroel, P. (2010). Psicología y Desastres Naturales: Terremoto y Tsunami: Del 27 de Febrero de 2010 en Chile. Terapia Psicológica, 28, 143-145. 
APPENDIX 1: Averages and standard deviations according to gender for valence and arousal

\begin{tabular}{|c|c|c|c|c|c|c|c|c|c|c|}
\hline \multirow{3}{*}{ IAPS } & \multicolumn{3}{|l|}{ Valence } & & & \multicolumn{3}{|l|}{ Arousal } & \multirow{3}{*}{$\mathrm{SD}$} & \\
\hline & Women & & Men & & & Women & & Men & & \\
\hline & Mean & $\mathrm{SD}$ & Mean & $\mathrm{SD}$ & & Mean & $\mathrm{SD}$ & Mean & & \\
\hline 1111 & 2.41 & 1.61 & 3.93 & 2.03 & $*$ & 6.45 & 2.64 & 4.86 & 2.55 & * \\
\hline 1114 & 3.21 & 2.14 & 4.87 & 2.00 & $*$ & 5.89 & 2.68 & 5.09 & 2.66 & \\
\hline 1201 & 3.21 & 1.99 & 5.07 & 2.12 & $*$ & 6.07 & 2.71 & 4.34 & 2.63 & $*$ \\
\hline 1205 & 2.58 & 1.83 & 4.35 & 2.16 & $*$ & 6.54 & 2.43 & 4.89 & 2.63 & $*$ \\
\hline 1302 & 3.53 & 1.98 & 4.73 & 1.95 & $*$ & 5.63 & 2.43 & 4.76 & 2.62 & \\
\hline 1661 & 5.90 & 2.01 & 5.67 & 1.56 & & 3.43 & 2.26 & 3.24 & 2.13 & \\
\hline 1726 & 5.07 & 2.56 & 5.81 & 2.25 & & 5.59 & 2.52 & 5.28 & 2.72 & \\
\hline 1731 & 6.85 & 1.76 & 7.12 & 1.81 & & 4.17 & 2.62 & 4.36 & 2.59 & \\
\hline 1811 & 7.21 & 2.04 & 7.12 & 1.99 & & 4.36 & 2.58 & 4.17 & 2.64 & \\
\hline 1931 & 3.57 & 2.33 & 5.19 & 2.20 & $*$ & 5.93 & 2.60 & 5.50 & 2.73 & \\
\hline 1935 & 3.83 & 1.95 & 4.87 & 1.44 & $*$ & 4.50 & 2.96 & 3.59 & 2.44 & \\
\hline 2025 & 5.26 & 1.60 & 6.37 & 1.61 & $*$ & 2.59 & 2.10 & 3.73 & 2.20 & * \\
\hline 2055 & 4.34 & 2.41 & 5.04 & 2.10 & & 5.33 & 2.50 & 4.68 & 2.54 & \\
\hline 2071 & 8.29 & 1.44 & 7.55 & 1.44 & $*$ & 5.00 & 2.86 & 3.65 & 2.72 & * \\
\hline 2091 & 7.95 & 1.64 & 7.04 & 1.72 & $*$ & 4.36 & 2.88 & 3.30 & 2.41 & $*$ \\
\hline 2092 & 5.88 & 2.45 & 5.57 & 2.23 & & 4.26 & 2.66 & 3.76 & 2.42 & \\
\hline 2095 & 1.42 & 1.04 & 2.08 & 1.42 & $*$ & 7.33 & 2.15 & 5.86 & 2.51 & $*$ \\
\hline 2191 & 5.78 & 1.73 & 6.13 & 1.78 & & 2.92 & 2.15 & 2.89 & 2.17 & \\
\hline 2222 & 7.47 & 1.54 & 6.28 & 1.69 & $*$ & 3.76 & 2.38 & 2.87 & 2.13 & $*$ \\
\hline 2224 & 7.77 & 1.50 & 6.72 & 1.51 & * & 3.73 & 2.63 & 3.28 & 2.32 & \\
\hline 2278 & 2.53 & 1.63 & 3.45 & 2.04 & $*$ & 5.18 & 2.55 & 4.44 & 2.54 & \\
\hline 2346 & 7.49 & 2.03 & 7.20 & 2.05 & & 4.65 & 2.78 & 4.32 & 2.70 & \\
\hline 2357 & 6.59 & 1.92 & 5.97 & 1.96 & & 3.04 & 2.37 & 2.83 & 2.10 & \\
\hline 2375 & 1.92 & 1.33 & 2.83 & 1.64 & $*$ & 6.11 & 2.45 & 4.97 & 2.33 & $*$ \\
\hline 2399 & 3.54 & 1.67 & 4.23 & 1.55 & $*$ & 3.44 & 2.22 & 3.24 & 2.37 & \\
\hline 2435 & 5.63 & 1.61 & 5.69 & 1.32 & & 2.56 & 1.93 & 2.66 & 2.04 & \\
\hline 2442 & 7.17 & 1.70 & 6.19 & 1.59 & $*$ & 3.33 & 2.46 & 2.92 & 2.16 & \\
\hline 2579 & 5.22 & 1.34 & 5.58 & 1.61 & & 2.92 & 1.98 & 2.98 & 2.15 & \\
\hline 2595 & 5.35 & 1.40 & 5.05 & 1.63 & & 2.65 & 1.87 & 2.81 & 1.98 & \\
\hline 2635 & 4.96 & 2.06 & 5.15 & 2.04 & & 4.14 & 2.40 & 4.12 & 2.46 & \\
\hline 2661 & 3.51 & 2.53 & 4.19 & 2.37 & & 6.39 & 2.47 & 5.29 & 2.46 & * \\
\hline 2688 & 1.83 & 1.57 & 2.89 & 2.15 & $*$ & 6.56 & 2.48 & 5.68 & 2.64 & \\
\hline 2691 & 3.20 & 1.74 & 4.63 & 2.11 & $*$ & 5.29 & 2.46 & 4.74 & 2.51 & \\
\hline 2745 & 5.32 & 1.33 & 5.16 & 1.03 & & 2.24 & 1.69 & 2.15 & 1.72 & \\
\hline 2795 & 3.24 & 1.98 & 3.59 & 1.62 & & 5.21 & 2.50 & 4.15 & 2.33 & * \\
\hline 2981 & 2.31 & 2.14 & 3.97 & 2.12 & $*$ & 6.72 & 2.49 & 5.19 & 2.73 & * \\
\hline 3053 & 1.40 & 1.10 & 2.14 & 1.83 & $*$ & 7.86 & 2.14 & 6.89 & 2.52 & * \\
\hline 3101 & 1.61 & 1.26 & 2.61 & 1.84 & $*$ & 7.23 & 2.17 & 5.89 & 2.50 & * \\
\hline 3102 & 1.64 & 1.51 & 2.60 & 1.94 & $*$ & 7.57 & 2.09 & 6.02 & 2.67 & $*$ \\
\hline 4001 & 4.76 & 1.46 & 7.03 & 1.88 & $*$ & 2.79 & 2.09 & 4.78 & 2.55 & $*$ \\
\hline 4002 & 4.86 & 1.41 & 7.07 & 1.70 & $*$ & 2.80 & 2.16 & 4.79 & 2.58 & $*$ \\
\hline 4004 & 4.95 & 1.36 & 6.38 & 1.75 & $*$ & 2.45 & 1.94 & 3.79 & 2.45 & $*$ \\
\hline 4141 & 4.68 & 1.49 & 7.58 & 1.33 & $*$ & 2.71 & 2.17 & 5.35 & 2.75 & $*$ \\
\hline 4503 & 5.76 & 1.94 & 4.92 & 1.34 & $*$ & 3.44 & 2.40 & 2.64 & 1.99 & \\
\hline 4534 & 6.32 & 1.70 & 4.97 & 1.40 & $*$ & 3.91 & 2.48 & 2.50 & 2.06 & $*$ \\
\hline 4535 & 6.59 & 1.93 & 5.57 & 1.65 & $*$ & 3.86 & 2.59 & 3.21 & 2.50 & \\
\hline 4538 & 7.18 & 1.71 & 4.88 & 1.17 & $*$ & 4.86 & 2.78 & 2.47 & 2.10 & $*$ \\
\hline 4603 & 6.89 & 1.81 & 6.39 & 1.83 & & 3.74 & 2.43 & 3.61 & 2.60 & \\
\hline 4607 & 6.37 & 1.63 & 7.24 & 1.60 & $*$ & 4.04 & 2.46 & 4.74 & 2.82 & \\
\hline 4608 & 6.82 & 1.72 & 7.30 & 1.64 & & 5.05 & 2.53 & 4.88 & 2.78 & \\
\hline
\end{tabular}


APPENDIX 1: Continued

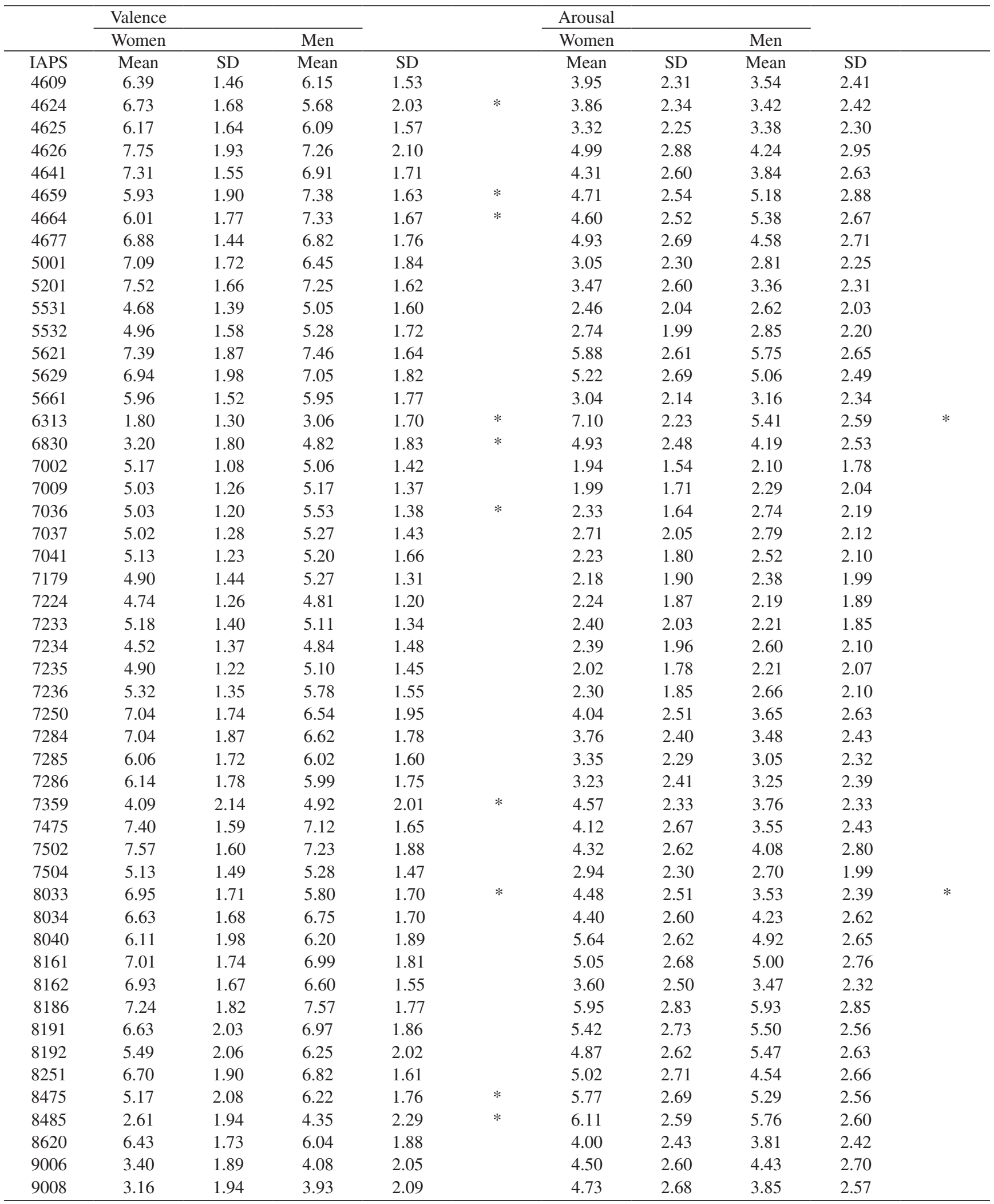


APPENDIX 1: Continued

\begin{tabular}{|c|c|c|c|c|c|c|c|c|c|c|}
\hline & \multicolumn{3}{|l|}{ Valence } & & & \multicolumn{3}{|l|}{ Arousal } & & \\
\hline & Women & & Men & & & Women & & Men & & \\
\hline IAPS & Mean & SD & Mean & SD & & Mean & SD & Mean & SD & \\
\hline 9182 & 3.55 & 2.30 & 4.30 & 2.02 & & 4.95 & 2.53 & 4.17 & 2.46 & \\
\hline 9252 & 1.83 & 1.40 & 3.22 & 1.95 & $*$ & 6.86 & 2.39 & 5.61 & 2.83 & * \\
\hline 9301 & 2.14 & 1.68 & 3.43 & 1.99 & $*$ & 6.91 & 2.39 & 5.35 & 2.74 & * \\
\hline 9342 & 2.43 & 1.58 & 3.48 & 1.81 & $*$ & 5.05 & 2.50 & 4.42 & 2.51 & \\
\hline 9373 & 3.12 & 1.83 & 4.18 & 1.79 & $*$ & 4.85 & 2.58 & 4.13 & 2.56 & \\
\hline 9409 & 3.09 & 1.59 & 4.60 & 1.85 & $*$ & 4.78 & 2.52 & 4.11 & 2.53 & \\
\hline 9411 & 4.12 & 1.90 & 5.27 & 2.05 & $*$ & 4.18 & 2.46 & 4.27 & 2.53 & \\
\hline 9432 & 2.38 & 1.57 & 3.08 & 1.71 & $*$ & 5.77 & 2.59 & 4.99 & 2.47 & \\
\hline 9452 & 3.39 & 1.87 & 4.51 & 1.75 & $*$ & 4.55 & 2.41 & 3.56 & 2.14 & $*$ \\
\hline 9470 & 2.64 & 1.53 & 3.91 & 2.06 & $*$ & 5.14 & 2.32 & 4.41 & 2.47 & \\
\hline 9471 & 2.68 & 1.49 & 3.67 & 1.92 & $*$ & 4.87 & 2.37 & 4.27 & 2.40 & \\
\hline 9472 & 4.18 & 1.40 & 4.48 & 1.51 & & 3.62 & 2.24 & 3.65 & 2.28 & \\
\hline 9495 & 2.55 & 1.64 & 4.17 & 1.85 & $*$ & 5.63 & 2.47 & 4.50 & 2.34 & * \\
\hline 9571 & 1.91 & 1.31 & 3.28 & 1.96 & $*$ & 6.23 & 2.61 & 4.69 & 2.69 & * \\
\hline 9621 & 3.85 & 1.60 & 4.56 & 1.55 & $*$ & 3.95 & 2.36 & 4.00 & 2.37 & \\
\hline 9622 & 2.93 & 1.73 & 4.25 & 2.10 & $*$ & 5.30 & 2.42 & 5.13 & 2.60 & \\
\hline 9635 & 1.64 & 1.32 & 2.90 & 2.04 & $*$ & 7.30 & 2.19 & 6.05 & 2.55 & $*$ \\
\hline 9911 & 2.30 & 1.37 & 3.62 & 1.70 & $*$ & 5.83 & 2.39 & 4.67 & 2.39 & $*$ \\
\hline
\end{tabular}

Note: IAPS=International Affective Picture System (slide number); ${ }^{*} p<.001$ 